\title{
Spatial epidemiology of COVID-19 infection through the first outbreak (March-May 2020) in the city of Mashhad, Iran
}

\section{Hasan Mansouritorghabeh}

Mashhad University of Medical Sciences

Ahmad Bagherimoghaddam

Mashhad University of Medical Sciences

Shahab MohammadEbrahimi

Mashhad University of Medical Sciences

\section{Saeid Eslami}

Mashhad University of Medical Sciences

Amene Raouf-Rahmati

Mashhad University of Medical Sciences

\section{Davidson H Hamer}

Boston University

Behzad Kiani ( $\sim$ Kiani.Behzad@gmail.com )

Mashhad University of Medical Sciences

\section{Research Article}

Keywords: COVID-19, Coronavirus, Geographic Information Systems, GIS, Spatial Analysis, SARS-CoV-2 infection, Spatial Clustering, Mapping

Posted Date: January 6th, 2021

DOl: https://doi.org/10.21203/rs.3.rs-141651/v1

License: (a) (1) This work is licensed under a Creative Commons Attribution 4.0 International License. Read Full License 


\section{Spatial epidemiology of COVID-19 infection through the first outbreak (March-May 2020) in the city of Mashhad, Iran}

Hasan Mansouritorghabeh ${ }^{1}$, Ahmad Bagherimoghaddam ${ }^{2}$, Shahab MohammadEbrahimi ${ }^{3,4}$, Saeid Eslami ${ }^{5}$, Amene Raouf-Rahmati ${ }^{6}$, Davidson H Hamer ${ }^{7-9}$, Behzad Kiani ${ }^{4}$

1- Central Diagnostic Laboratories, Ghaem Hospital, Mashhad University of Medical Sciences, Mashhad, Iran.

2- Department of Anesthesiology, Internal Medicine and Critical Care Division, Mashhad University of Medical Science, Mashhad, Iran.

3- Department of Medical Informatics, School of Medicine, Mashhad University of Medical Sciences, Mashhad, Iran

4- Student Research Committee, Mashhad University of Medical Sciences, Mashhad, Iran

5- Pharmaceutical Research Center, Mashhad University of Medical Science, Mashhad, Iran.

6- Department of Parasitology, Mashhad University of Medical Sciences, Mashhad, Iran

7- Department of Global Health, Boston University, School of Public Health, Boston, MA, USA

8- Section of Infectious Disease, Department of Medicine, Boston University, School of Medicine, Boston, MA, USA

9- National Emerging Infectious Disease Laboratory, Boston University, Boston, Massachusetts.

Correspondence to: Behzad Kiani, Department of Medical Informatics, School of Medicine, Mashhad University of Medical Sciences, Mashhad, Iran. E-mail: Kianib@mums.ac.ir Tel: +989120652983 


\section{Abstract:}

Background: Since December 2019, SARS-CoV-2 infection has converted to a severe threat to global health. It is now considered as the fifth worldwide pandemic problem. This study aims to explore spatial-time distribution of COVID-19 in the first outbreak of COVID-19 in the second major city of Iran (Mashhad). The results will pave the way for better tracking of COVID-19.

Methods: Data were collected from two tertiary hospitals in Mashhad in June 2020. They included demographic findings and residential address of the patients with confirmed COVID-19 disease by polymerase chain reaction test. The univariate logistic regression model was used to assess the influence of age and sex on mortality. For spatial-time analysis, after calculating empirical Bayesian rate for every neighborhood, the local Moran's $I$ statistic was used to quantify spatial autocorrelation of COVID-19 frequency at the city neighborhood level.

Results: Of 1,535 confirmed cases of COVID-19 included in this study, 951 (62\%) were male. Odds of death for patients over 60 years of age was more than three times higher (odds ratio [OR]: 3.7, CI [2.8-4.8]) than for those under the 60 years. In addition, the ratio of relative mortality for male patients was significantly higher than the female (OR: 1.58, CI [1.2-2]). The univariate regression model also revealed that odds of death increased along with increase in duration of hospitalization secondary to COVID-19 disease (OR: 1.02, IQR [1.01-1.02]). The downtown area had a significant high-high cluster throughout much of the study period (March-May 2020).

Conclusions: Collection of geographic information system (GIS) map data on SARS-CoV-2 provides insight into clusters of infection and high risk places for COVID-19 transmission. GISbased map could potentially be used to predict future places of involvement for health systems.

Keywords: COVID-19, Coronavirus, Geographic Information Systems, GIS, Spatial Analysis, SARS-CoV-2 infection, Spatial Clustering, Mapping 


\section{Background:}

The 7th member of the coronavirus family began spreading across the world in December 2019 after being identified in a seafood market in Wuhan, China (1). The World Health Organization (WHO) named the newly emerged virus, severe acute respiratory syndrome coronavirus 2 (SARSCoV-2) and the disease that it causes, coronavirus disease 2019 (COVID-19) in Jan 7, 2020 (2). The citizens who traveled from Wuhan City were leading sources of transmission of COVID-19 to the rest of China (3). Restriction measures introduced at Wuhan to control the spread of COVID19 included rapid isolation of confirmed and suspected cases, clinical management of affected patients, enhanced medical testing, closure of entertainment facilities, prohibition of public meetings, and, eventually, restriction of movement $(4,5)$. Despite meeting these restriction measures, SARS-CoV-2 virus spread much faster than previously anticipated. Iran was one of the earlier affected countries might be due to high economic relations with China (6). The religious city of Qom was among the earlier affected cities in the country (7) which have direct air flight and high religious relations with Mashhad City.

The number of infected cases and deaths is still increasing rapidly. In developing countries, where there is high population density, accelerated urbanization, and shortage of medical services, inhibition of COVID-19 spread is difficult (8). Furthermore, an unprecedented health issue, economic challenges, and feeling of discontent and sentiments created for global population (9). In the other hand, COVID19 spread through the body's processes 100 times faster than related viruses (10).

In 1694, the association between place and health (containment of plagues) developed in Italy (11). The map's vital position in the monitoring of infectious diseases in pandemics was subsequently accepted (12). The development of geographical information systems (GIS) allowed further study and identification of disease patterns (13). In fact, a revolution has arisen in the area of infectious diseases, by engaging health geography with web-based resources. We assume that GIS will help the numerous countries fight more effectively against COVID-19 through finding high-risk areas in each city. GIS can play a leading role in managing the COVID-19 epidemic as seen earlier (8). Given that, knowledge of the distribution of COVID-19 in highly endemic regions is important for provision of health care services and for planning the residence of the region. Here, we explore and examine the temporal and spatial distribution of COVID-19 in the first outbreak of COVID- 
19 in the second major city of Iran (Mashhad). We hope that in future these data resulting from the study of GIS applications will pave the way for better tracking of COVID-19, but also for planning health services, medications, hospital and intensive care unit (ICU) capacity, etc.

\section{Methods:}

\section{Study Area:}

This study was conducted in the city of Mashhad, the capital of Khorasan-Razavi Province and the second most populous city in Iran. Mashhad, located in northeastern Iran, has a estimated metro population of 3,208,000 according to $1.78 \%$ increase from 2019 (14). Mashhad has the highest number of tourists in Iran every year because it is the religious center of Iran. Figure 1 indicates the region being investigated.

Figure 1: Study area location with COVID-19 spatial distribution map

\section{Patients and methods:}

Data were collected from two tertiary hospitals in Mashhad in June 2020. Hence, all admitted patients with ICD (international code of disease) number U07.1 extracted from medical records offices of the two hospitals during March-May 2020. To accomplish this aim, a questionnaire was prepared and filled out for each patient.

\section{Statistical Methods:}

Continuous variables were represented as median and interquartile range (IQR) and compared by the Mann-Whitney U test. Categorical variables were expressed as number (\%) and compared once between males and females and once between survivors and non-survivors by $\chi^{2}$ test or Fisher's exact. The univariate logistic regression model was used to assess the influence of age and sex on mortality. Un-adjusted odds ratios (OR) with 95\% confidence intervals (CI) were calculated and reported. All tests were two-sided, and $\alpha$ of less than 0.05 was considered statistically significant. All statistical analyses were performed using R software, version 4.0.5 (R Foundation for Statistical Computing) and Microsoft Excel version 16.

\section{Spatial Time Analysis:}

The core concept behind the hierarchical Bayesian model that used in the current study is that in each area-specific incidence is based on pooling information from neighboring areas (prior distribution). Methodological aspects of the Bayesian analysis applied to geographical clustering have been reported in a previous study (15). After calculating the empirical Bayesian rate (EBR) 
for every neighborhood, the local Moran's I statistic (16) was used to quantify spatial autocorrelation of COVID-19 frequency at the city neighborhood level. This test calculates a zscore and p-value to determine whether the apparent similarity (spatial clustering of either high or low values) or dissimilarity (presence of spatial outliers) is more pronounced than predicted in a random distribution. The null hypothesis suggests that the COVID-19 cases are randomly distributed throughout the sample region. An extremely positive z-score for a feature indicates that the surrounding features have similar values (either high values or low values). However, a low negative z-score for a feature suggests a statistically significant spatial data outlier (16). We used a $95 \%$ confidence level (CL), and all the clusters and outliers found in this study were significant at this CL. We used ArcGIS, v. 10.5 (ESRI, Redlands, CA, USA) and GeoDa (https://spatial.uchicago.edu/geoda) for spatial analyses.

\section{Results:}

In this section, the statistical results are first reported and then the spatio-temporal results are discussed.

\section{Statistical results:}

Considering 1,535 confirmed cases of COVID-19 included in this study, 951 (62\%) and 584 (38\%) were male and female, respectively. Table 1 shows a comparison between sex groups and in addition reveals a comparison based on patients' health outcomes. As a result, two classes of nonsurvivors $(n=356,23.2 \%)$ and survivors $(n=1,179,76.8 \%)$ were compared.

\section{Age and sex}

The median age of all patients was 62 years (IQR [47-73]). Sixteen cases (1.0\%) were younger than 20 years and $842(54.8 \%)$ of them were older than 60 years. Women were marginally older (one year on average) and they had no significant differences in terms of age-groups and length of stay (LOS), which is the span from hospital entry to death or discharge, compared to men. More men $(n=951)$ than women $(n=584)$ were admitted to these two tertiary hospitals, because of SARSCoV-2 infection. In fact, among the 356 non-survivor cases of COVID-19, the ratio of male to female was $70 \%(n=249)$ to $30 \%(n=107)$. 
Table 1. Baseline characteristics of 1,535 COVID-19 patients disaggregated by sex and disease outcomes

\begin{tabular}{|c|c|c|c|c|c|c|c|}
\hline Variable & $\begin{array}{c}\text { Total } \\
(\mathbf{1 , 5 3 5 )}\end{array}$ & $\begin{array}{l}\text { Male } \\
(951)\end{array}$ & $\begin{array}{c}\text { Female } \\
(584)\end{array}$ & $\begin{array}{c}\text { p- } \\
\text { value }\end{array}$ & $\begin{array}{c}\text { Non- } \\
\text { Survivors } \\
(356) \\
\end{array}$ & $\begin{array}{c}\text { Survivors } \\
(\mathbf{1 , 1 7 9 )}\end{array}$ & p-value \\
\hline \multicolumn{8}{|l|}{ Age (years) } \\
\hline $\begin{array}{l}\text { Median } \\
\text { (IQR) }\end{array}$ & $\begin{array}{c}62.0 \\
(47.0- \\
73.0)\end{array}$ & $\begin{array}{c}61.0 \\
(47.0- \\
73.0)\end{array}$ & $\begin{array}{c}62.0 \\
(49.0- \\
73.0)\end{array}$ & 0.6264 & $\begin{array}{c}70.0(60.0- \\
82.0)\end{array}$ & $\begin{array}{c}59.0(44.0- \\
70.0)\end{array}$ & $<0.0001$ \\
\hline \multicolumn{8}{|l|}{ Age groups (years) } \\
\hline$<10$ & $4(0.3)$ & $3(0.3)$ & $1(0.2)$ & \multirow{10}{*}{0.7789} & $2(0.56)$ & $2(0.2)$ & \multirow{10}{*}{$<0.0001$} \\
\hline $10-19$ & $12(0.8)$ & $8(0.8)$ & $4(0.7)$ & & $1(0.28)$ & $11(0.9)$ & \\
\hline $20-29$ & $52(3.4)$ & $28(2.9)$ & $24(4.1)$ & & $4(1.12)$ & $48(4.07)$ & \\
\hline $30-39$ & $144(9.4)$ & $89(9.4)$ & $55(9.4)$ & & $9(2.52)$ & $135(11.5)$ & \\
\hline $40-49$ & $\begin{array}{c}202 \\
(13.2)\end{array}$ & $\begin{array}{c}132 \\
(13.9)\end{array}$ & $70(12)$ & & $19(5.3)$ & $183(15.5)$ & \\
\hline $50-59$ & $\begin{array}{c}279 \\
(18.2)\end{array}$ & $\begin{array}{c}172 \\
(18.1)\end{array}$ & $\begin{array}{c}107 \\
(18.3)\end{array}$ & & $46(12.9)$ & $233(19.8)$ & \\
\hline $60-69$ & $\begin{array}{c}361 \\
(23.5)\end{array}$ & $\begin{array}{c}231 \\
(24.3)\end{array}$ & $\begin{array}{c}130 \\
(22.3)\end{array}$ & & $91(25.6)$ & $270(22.9)$ & \\
\hline $70-79$ & $\begin{array}{c}247 \\
(16.1)\end{array}$ & $\begin{array}{c}142 \\
(14.9)\end{array}$ & $105(18)$ & & $75(21.1)$ & $172(14.6)$ & \\
\hline $80-89$ & $\begin{array}{c}188 \\
(12.2)\end{array}$ & $\begin{array}{c}117 \\
(12.3)\end{array}$ & $71(12.2)$ & & 77 (21.6) & $111(9.4)$ & \\
\hline$>90$ & $46(3)$ & $29(3)$ & $17(2.9)$ & & $32(9)$ & $14(1.2)$ & \\
\hline \multicolumn{8}{|l|}{ LOS } \\
\hline $\begin{array}{l}\text { Median } \\
\text { (IQR) }\end{array}$ & $\begin{array}{c}7.0(4.0- \\
13.0)\end{array}$ & $\begin{array}{c}7.0(4.0- \\
13.0)\end{array}$ & $\begin{array}{c}7.0(4.0- \\
12.0)\end{array}$ & 0.6646 & $9.0(4.0-23.0)$ & $\begin{array}{c}6.0(4.0- \\
11.0)\end{array}$ & $<0.0001$ \\
\hline \multicolumn{8}{|l|}{ Sex } \\
\hline Male & $951(62)$ & - & - & - & $249(69.95)$ & $702(59.54)$ & \multirow[b]{2}{*}{0.0003} \\
\hline Female & $\begin{array}{c}584 \\
(38.1)\end{array}$ & - & - & - & $107(30.05)$ & $477(40.46)$ & \\
\hline \multicolumn{8}{|l|}{ Outcome } \\
\hline $\begin{array}{l}\text { Non- } \\
\text { Survivors }\end{array}$ & $\begin{array}{c}356 \\
(23.2)\end{array}$ & $\begin{array}{c}249 \\
(26.2)\end{array}$ & $\begin{array}{c}107 \\
(18.3)\end{array}$ & \multirow{2}{*}{0.0003} & - & - & - \\
\hline Survivors & $\begin{array}{l}1,179 \\
(76.8)\end{array}$ & $\begin{array}{c}702 \\
(73.8)\end{array}$ & $\begin{array}{c}477 \\
(81.7)\end{array}$ & & - & - & - \\
\hline
\end{tabular}

IQR: Inter Quartile Range, LOS: Length of Stay.

\section{Patient outcomes}

As mentioned earlier, there were two types of outcomes in our results. As can be seen in Table 1, nearly $76.8 \%$ of patients were discharged alive and the remainder died $(23.2 \%)$ in these two tertiary hospitals. The median age of non-survivors (70, IQR [60-82]) was significantly (11 years) older than survivors $(59$, IQR [44-70]), (p: <0.0001). By stratifying the age into 10 categories (10 year intervals), the rate of infection fatality is presented by each age group. Accordingly, as shown in Figure 2, almost two percent of all deaths (7/356), occurred among the three first age groups $(<10$, 10-19, and 20-29). The highest frequency of infection with COVID-19 was found in the age group 
of 60-69 years (23.5\%). Mortality rates increased with age, so that in each of the four upper age groups $(60-69,70-79,80-89$, and $>90)$, there were mortality rates of $25.2 \%(91 / 361), 30.4 \%$ (75/247), $41.0 \%$ (77/188), and 69.6\% (32/46) respectively. In the current study, 77.2\% (275/356) of all fatalities caused by SARS-CoV-2 infection occurred at ages above 60 years. Notably, there was a substantial disparity between those who died (9 days, IQR [4-23]) and those who survived (6 days, IQR [4-11]) in the median LOS.

Figure 2. The distribution of all cases and deaths in each age group $(n=1,535)$.

\section{Risk factors}

By using the variables in the univariate logistic regression model, it was found that older age $(\geq 60$ years), male sex, and longer LOS were associated with increased risk of death (Table 2). According to this, odds of death for patients over 60 years of age was more than three times higher (OR: 3.66, CI [2.79-4.81]) than for those under 60 years. The odds of dying for male patients was significantly higher than females (OR: 1.58, CI [1.23-2.04]). The univariate regression model also revealed that odds of death increased slightly with an increase in period of stay due to COVID-19 disease (OR: 1.02, IQR [1.01-1.02]).

Table 2. Odds of death due to COVID-19, based on the affective factors

\begin{tabular}{|c|c|c|c|}
\hline Characteristic & OR & $95 \% \mathrm{CI}$ & p-value \\
\hline \multicolumn{4}{|l|}{ Age } \\
\hline$(<60)$ & - & - & - \\
\hline$(>=60)$ & 3.66 & 2.79_4.81 & $<0.001$ \\
\hline \multicolumn{4}{|l|}{ Sex } \\
\hline Female & - & - & - \\
\hline Male & 1.58 & $1.23 \_2.04$ & $<0.001$ \\
\hline LOS (day) & 1.02 & 1.01_1.02 & $<0.001$ \\
\hline
\end{tabular}

\section{Spatial Time Analysis:}

Figure 3 shows the spatial-time distribution of patients with COVID-19 in the region. Between 31 March to 13 April, the number of COVID-19 patients decreased.

Figure 3. Spatial-time distribution of Covid-19 patients in the city of Mashhad Figure 4 shows the spatial-time clusters of COVID-19 patients in the study area. The figure reveals that the downtown area had a significant high-high cluster throughout much of the period.

Figure 4. Spatial-time clusters of Covid-19 patients in the city of Mashhad 
The four categories shown in Figure 4 correspond to the four quadrants in the Moran scatter plots as shown in Figure 5. If nearby or neighboring areas are more identical, this is understood as positive spatial autocorrelation. Negative autocorrelation describes patterns that vary from neighboring areas. For example, the first scatter plot (which shows the neighborhood level Covid19 for 04 - 17 February) has a Moran's value of -0.017 that should be interpreted as a spatial random pattern. Note that the EBR values have been standardized and are specified in standard deviational units (the mean is zero and the standard deviation is 1). Similarly, the EBR spatial lag was computed for these standardized values (Figure 5).

Figure 5. Spatial-time of Moran's scatter plots of Covid-19 patients in the city of Mashhad.

\section{Discussion:}

Older people in the Mashhad population were more infected than younger people in the same population as predicted. Higher mortality rates prevailed in the three classes 6-79, 70-89, and 8089 years of age. This could be secondary to aging-related immune senescence, more underlying risk factors (co-morbid medical conditions) and potentially other factors that have not been identified. in older ages relative to younger ages. The number of infected male patients admitted to the two tertiary hospitals was greater than the number of infected women admitted to the same hospitals. As a result, with age falling, the number of affected patients admitted to hospitals was smaller. Of the three younger classes, those who usually less engaging with social activities in the society often had lower infections. Moreover, the natural power of the immune systems in the cited groups has influencing power too. This tendency may be secondary due to more presence and activities of males in the community than females. Hence, the number of non-survivals were higher in male compare to females. LOS was higher in non-survivals. Taken together death episodes were higher in infected persons over 60 years of age, it appears that this may be seen as a higher LOS predictor at the time of entry.

The spatial-time distribution figure scientifically portrayed that incidence of SARS-CoV-2 infection was nearly random in Mashhad in the first outbreak of the virus. However, it spread quickly to downtown, which is often more congested with people. In the middle of Mashhad, there is a holy shrine with numerous visitors and multiple roofed malls. These results may be consistent with the hypothesis that emphasize on the role of social distances and closed-air spaces in the 
spread of SARS-CoV-2 infections. This may be a central concept for the prevention of contamination through health care provider programs.

There is no doubt that GIS-based map of distribution of SARS-CoV-2 infection though various societies can support health care providers systems as a key component in avoiding and managing the spread of infection (17). Some researchers paid for this theme and provided a GIS-based Map of COVID-19 infection in the area concerned, including Italy (18), the USA (19), Pakistan (17) and India (20). Although, each GIS-based map has local benefit in showing directional distribution and trend of SARS-CoV-2 in the same society, it will help epidemiologists to better understanding the behaviors of the virus. Gathering such data and analyzing them through a meta-analysis may provide interesting findings about pattern of distribution of SARS-CoV-2 in various geographic regions of the world.

It is clear that lockdown of cities can be a great solution to control and prevent the spread of the disease. In Iran, the lack of public awareness promoted the rapid spread of COVID-19 and the rate of hospital admission and mortality increased dramatically (Figure 4). However, by raising public awareness about the seriousness of the COVID-19 threat, imposing travel restrictions and closing schools and universities as mentioned by Abdollahi et al (21) as an effective factor on reducing the burden of COVID-19, the first peak of outbreak was eventually largely controlled. But perhaps the most important factor in this control was the annual Iranian Nowruz two-week holiday. Starting on March 20, it turned out to be a useful excuse for a national lockdown, e.g., already on March 14 , one week before holiday, the largest commercial and pilgrimage centre in the downtown of the

city was closed due to the outbreak of COVID-19. This shows that a timely urban policy can be very effective approach. However, due to the economic fragility of Iranian community, the closure of the central parts of the cities cannot be sustained for the longer term. Due to the complex nature of COVID-19 pandemic, short-term temporal and spatial policies can fail. Hence, more efficient space-time policies are needed.

\section{Limitations:}

During data mining from the medical records, there were 25 records with false address of residence that were not included in the report. In fact, the total number of individuals registered with COVID19 was 1560 in two hospitals. There is shame in cultures regarding infection with COVID-19 (22, 23). This stigma and fear of future follow-up led a minority of people to write incorrect addresses 
in their medical records. Another limitation is a lack of data on underlying medical comorbidities and how this influenced mortality. In addition, in the current study only using address of residence was utilized as a risk factor for infection and death but we do not know where people have traveled within Mashhad or outsides. Hence, it is not possible to attribute acquisition of infection to the neighborhood of residence.

\section{Conclusion:}

The collection of GIS-based mapping data is essential for understanding the distribution of SARSCoV-2 infection within a city or region. These data can be used to show fronts of infection and high risk places for transmission of COVID-19 infection. GIS based maps will predict future places of involvement for health systems. It seems this would be considered as a necessary step in the current global health challenge.

\section{List of abbreviations:}

Geographic Information System (GIS); World Health Organization (WHO); Intensive Care Unit (ICU); International Code of Disease (ICD); Interquartile Range (IQR); Odds Ratios (OR); Confidence Intervals (CI); Empirical Bayesian Rate (EBR); Length of Stay (LOS)

\section{Declarations:}

\section{Ethics approval and consent to participate:}

This study has been approved by the ethical committee of Mashhad University of Medical Sciences (Reference number: IR.MUMS.REC.1398.312)

\section{Consent for publication:}

Not applicable

\section{Availability of data and materials:}

The datasets used and/or analysed during the current study are available from the corresponding author on reasonable request.

\section{Competing interests:}

The authors declare that they have no competing of interest. 


\section{Funding:}

The study was funded by Vice Chancellor of Research in Mashhad University of Medical Sciences (grant number 981796).

\section{Authors' contributions:}

H.M and B.K drafted the study. S.M performed statistical analyses. B.K performed spatial analyses. D.H.H critically reviewed the manuscript and contributed to manuscript writing. A.R.R geocoded the data. S.E and A.B contributed to data gathering and reviewing the text. B.K was the research leader and communicator with the journal. All authors reviewed and approved the final version for submission.

\section{Acknowledgements:}

We would like to thank Mashhad University of Medical Sciences for funding this study.

\section{References:}

1. Phelan AL, Katz R, Gostin LO. The novel coronavirus originating in Wuhan, China: challenges for global health governance. Jama. 2020;323(8):709-10.

2. Gorbalenya AE, Baker SC, Baric R, Groot RJd, Drosten C, Gulyaeva AA, et al. Severe acute respiratory syndrome-related coronavirus: The species and its viruses-a statement of the Coronavirus Study Group. 2020.

3. Chen Z-L, Zhang Q, Lu Y, Guo Z-M, Zhang X, Zhang W-J, et al. Distribution of the COVID-19 epidemic and correlation with population emigration from Wuhan, China. Chinese medical journal. 2020.

4. Kraemer MU, Yang C-H, Gutierrez B, Wu C-H, Klein B, Pigott DM, et al. The effect of human mobility and control measures on the COVID-19 epidemic in China. Science. 2020;368(6490):493-7.

5. Tian H, Liu Y, Li Y, Wu C-H, Chen B, Kraemer MU, et al. An investigation of transmission control measures during the first 50 days of the COVID-19 epidemic in China. Science. 2020;368(6491):638-42. 6. Jamshidi B, Rezaei M, Najafi F, Sheikhi A. The prediction of COVID-19 spread in Iran from 15 March to 15 April 2020. Iranian Red Crescent Medical Journal. 2020;22(5).

7. Salimi R, Gomar R, Heshmati B. The COVID-19 outbreak in Iran. Journal of global health. 2020;10(1).

8. Zhou C, Su F, Pei T, Zhang A, Du Y, Luo B, et al. COVID-19: Challenges to GIS with big data. Geography and Sustainability. 2020.

9. Stier A, Berman M, Bettencourt L. COVID-19 attack rate increases with city size. Mansueto Institute for Urban Innovation Research Paper Forthcoming. 2020.

10. Sigrist CJ, Bridge A, Le Mercier P. A potential role for integrins in host cell entry by SARS-CoV-2. Antiviral research. 2020;177:104759.

11. Koch T, Koch T. Cartographies of disease: maps, mapping, and medicine: Esri Press Redlands, CA; 2005.

12. Boulos MNK, Geraghty EM. Geographical tracking and mapping of coronavirus disease COVID19/severe acute respiratory syndrome coronavirus 2 (SARS-CoV-2) epidemic and associated events 
around the world: how 21st century GIS technologies are supporting the global fight against outbreaks and epidemics. BioMed Central; 2020.

13. Lyseen A, Nøhr C, Sørensen E, Gudes O, Geraghty E, Shaw N, et al. IMIA Health GIS Working Group A review and framework for categorizing current research and development in health related geographical information systems (GIS) studies. Yearb Med Inform. 2014;9:110-24.

14. Macrotrends. Mashhad, Iran Metro Area Population 1950-2020 [13 December 2020]. Available from: https://www.macrotrends.net/cities/21508/mashhad/population.

15. Marek L, Pászto V, Tuček P. Bayesian Mapping of Medical Data. In: Brus J, Vondrakova A, Vozenilek V, editors. Modern Trends in Cartography: Selected Papers of CARTOCON 2014. Cham: Springer International Publishing; 2015. p. 489-505.

16. Anselin L. Local indicators of spatial association-LISA. Geographical analysis. 1995;27(2):93-115.

17. Sarwar S, Waheed R, Sarwar S, Khan A. COVID-19 challenges to Pakistan: Is GIS analysis useful to draw solutions? Science of The Total Environment. 2020:139089.

18. Martellucci CA, Sah R, Rabaan AA, Dhama K, Casalone C, Arteaga-Livias K, et al. Changes in the spatial distribution of COVID-19 incidence in Italy using GIS-based maps. Annals of Clinical Microbiology and Antimicrobials. 2020;19(1):1-4.

19. Mollalo A, Vahedi B, Rivera KM. GIS-based spatial modeling of COVID-19 incidence rate in the continental United States. Science of The Total Environment. 2020:138884.

20. Bag R, Ghosh M, Biswas B, Chatterjee M. Understanding the spatio-temporal pattern of COVID19 outbreak in India using GIS and India's response in managing the Pandemic. Regional Science Policy \& Practice. 2020.

21. Abdollahi E, Haworth-Brockman M, Keynan Y, Langley JM, Moghadas SM. Simulating the effect of school closure during COVID-19 outbreaks in Ontario, Canada. BMC medicine. 2020;18(1):1-8.

22. Villa S, Jaramillo E, Mangioni D, Bandera A, Gori A, Raviglione MC. Stigma at the time of the COVID-19 pandemic. Clinical Microbiology and Infection. 2020.

23. Bhattacharya P, Banerjee D, Rao TS. The "untold" side of COVID-19: Social stigma and its consequences in India. Indian Journal of Psychological Medicine. 2020;42(4):382-6. 


\section{Figures:}

Figure 1: Study area location with COVID-19 spatial distribution map

Figure 2: The distribution of all cases and deaths in each age group $(n=1,535)$

Figure 3: Spatial-time distribution of Covid-19 patients in the city of Mashhad

Figure 4: Spatial-time clusters of Covid-19 patients in the city of Mashhad

Figure 5: Spatial-time of Moran's scatter plots of Covid-19 patients in the city of Mashhad 
Figures
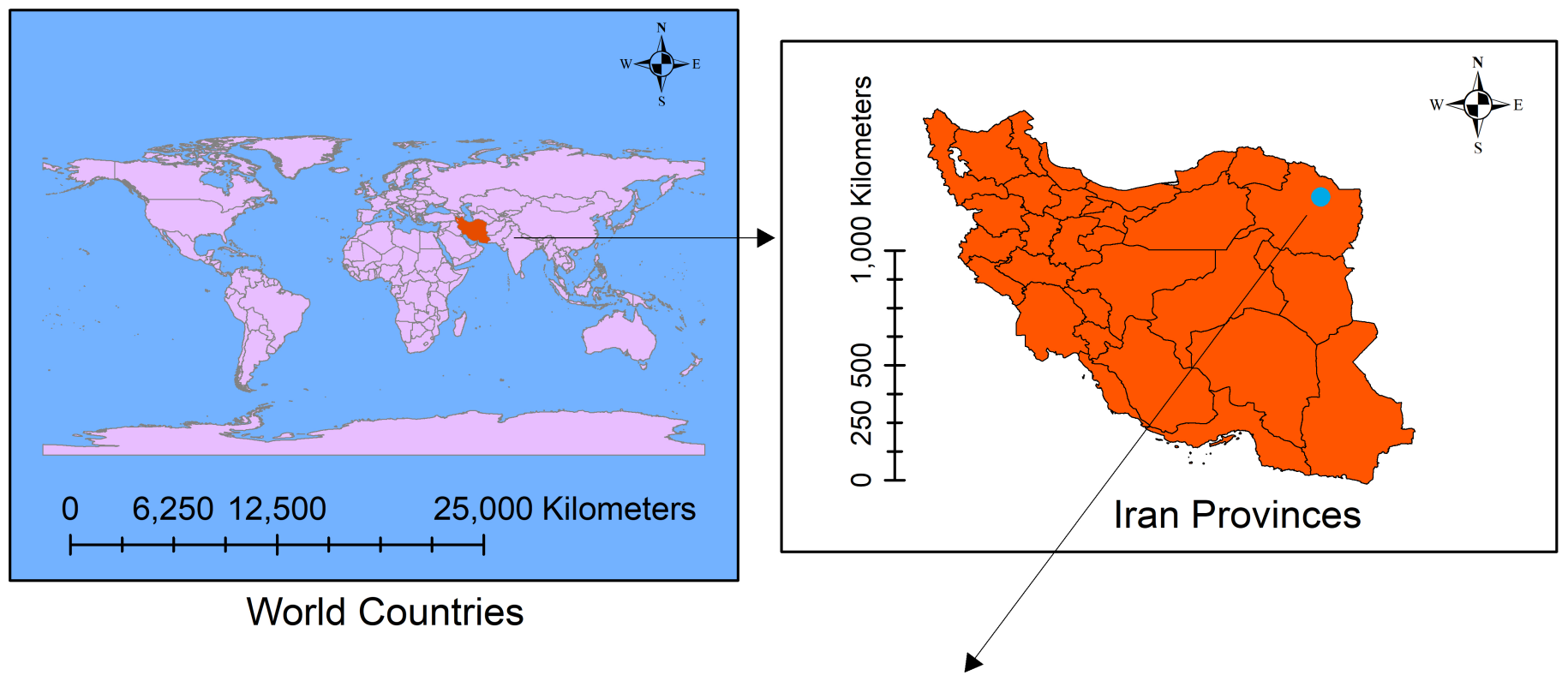

World Countries

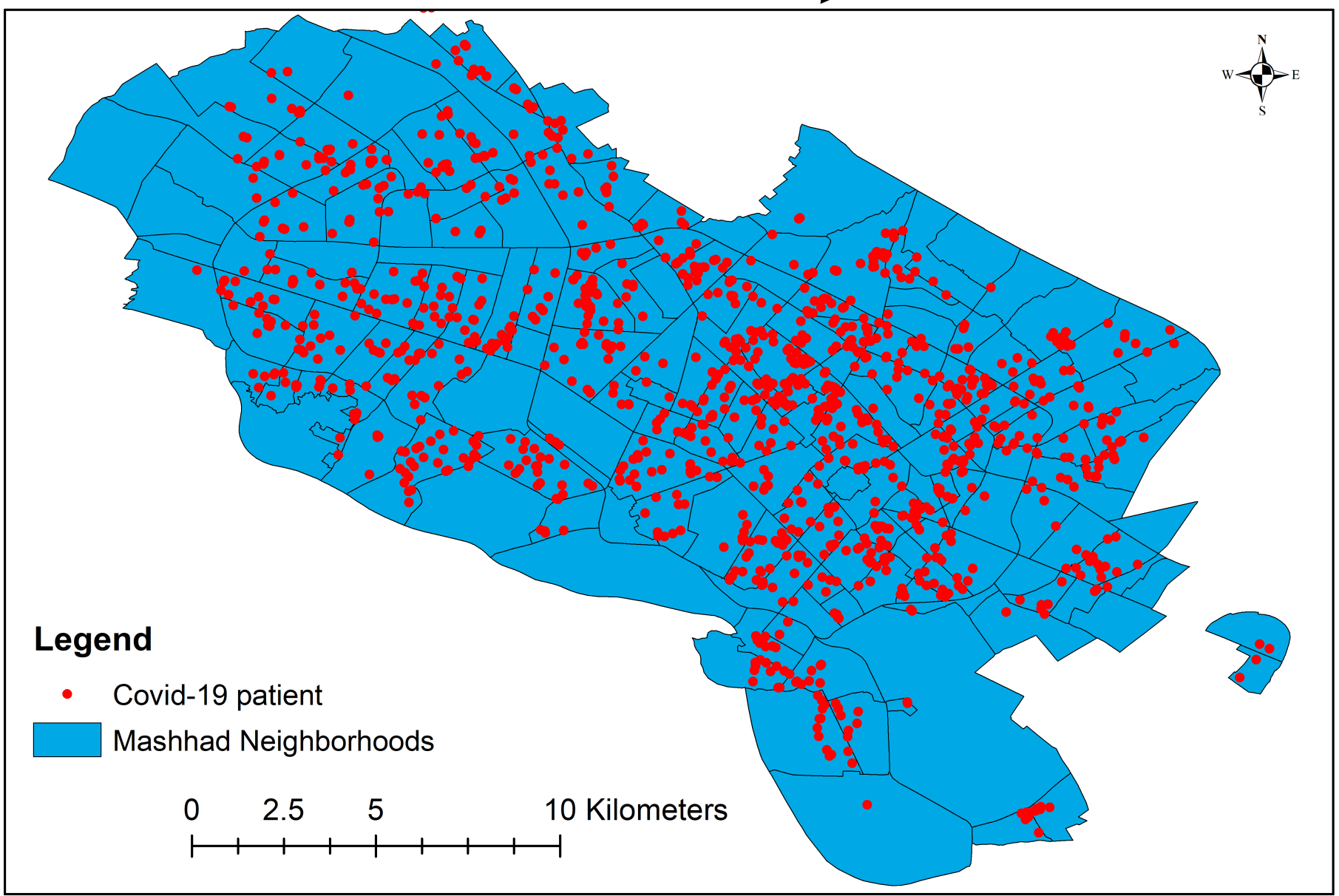

Figure 1

Study area location with COVID-19 spatial distribution map 

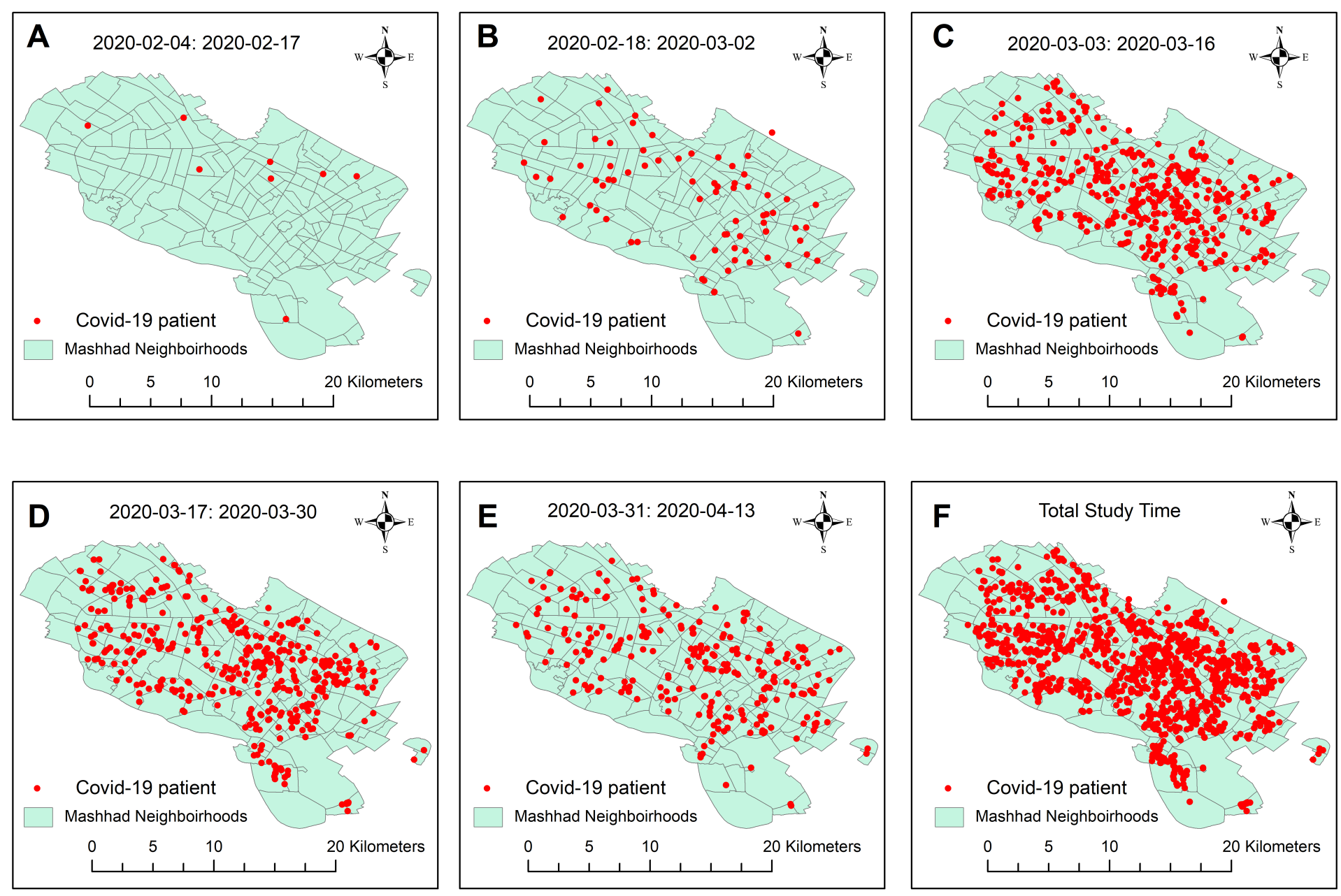

Figure 2

The distribution of all cases and deaths in each age group $(n=1,535)$ 

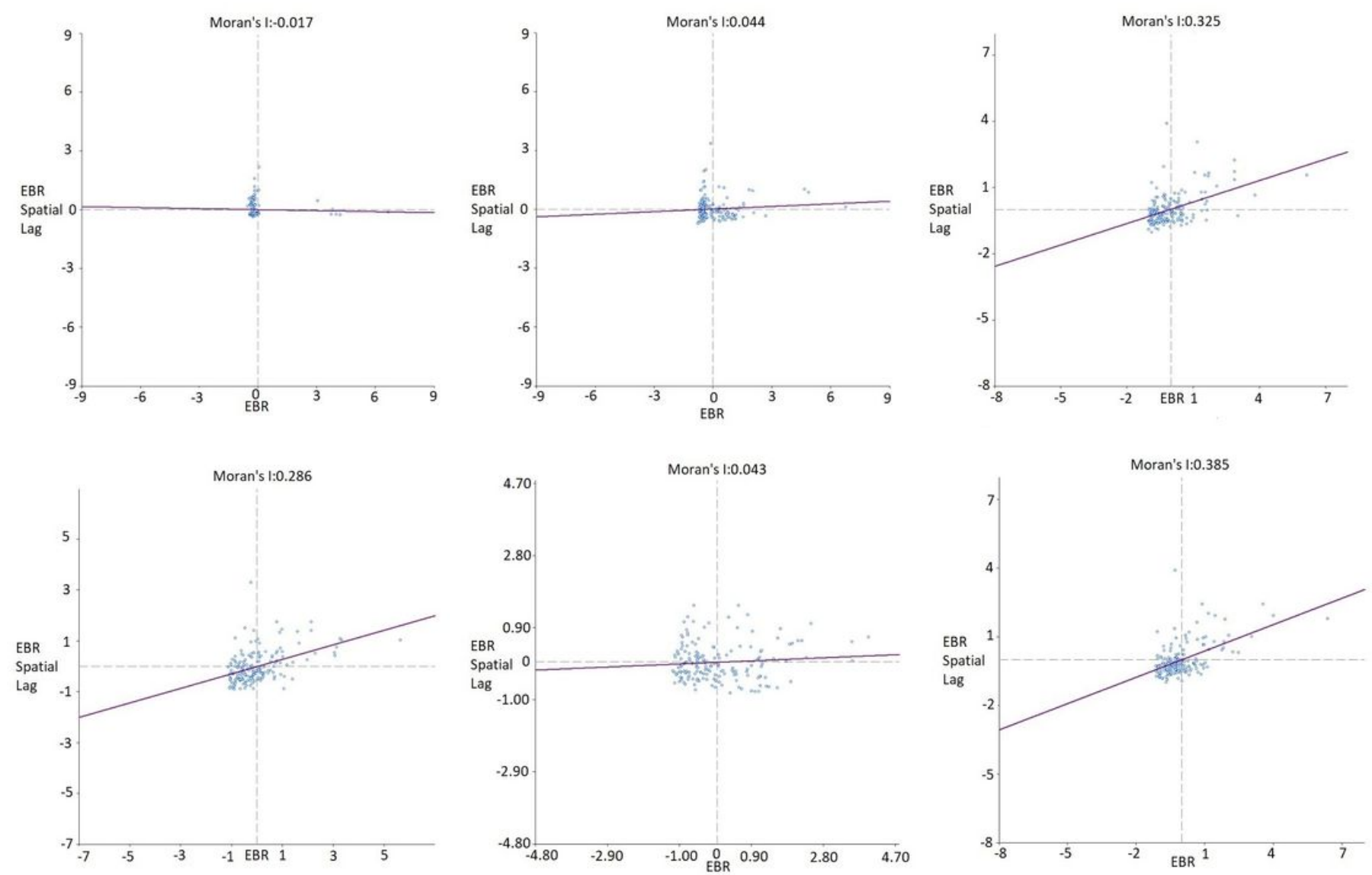

Figure 3

Spatial-time distribution of Covid-19 patients in the city of Mashhad 

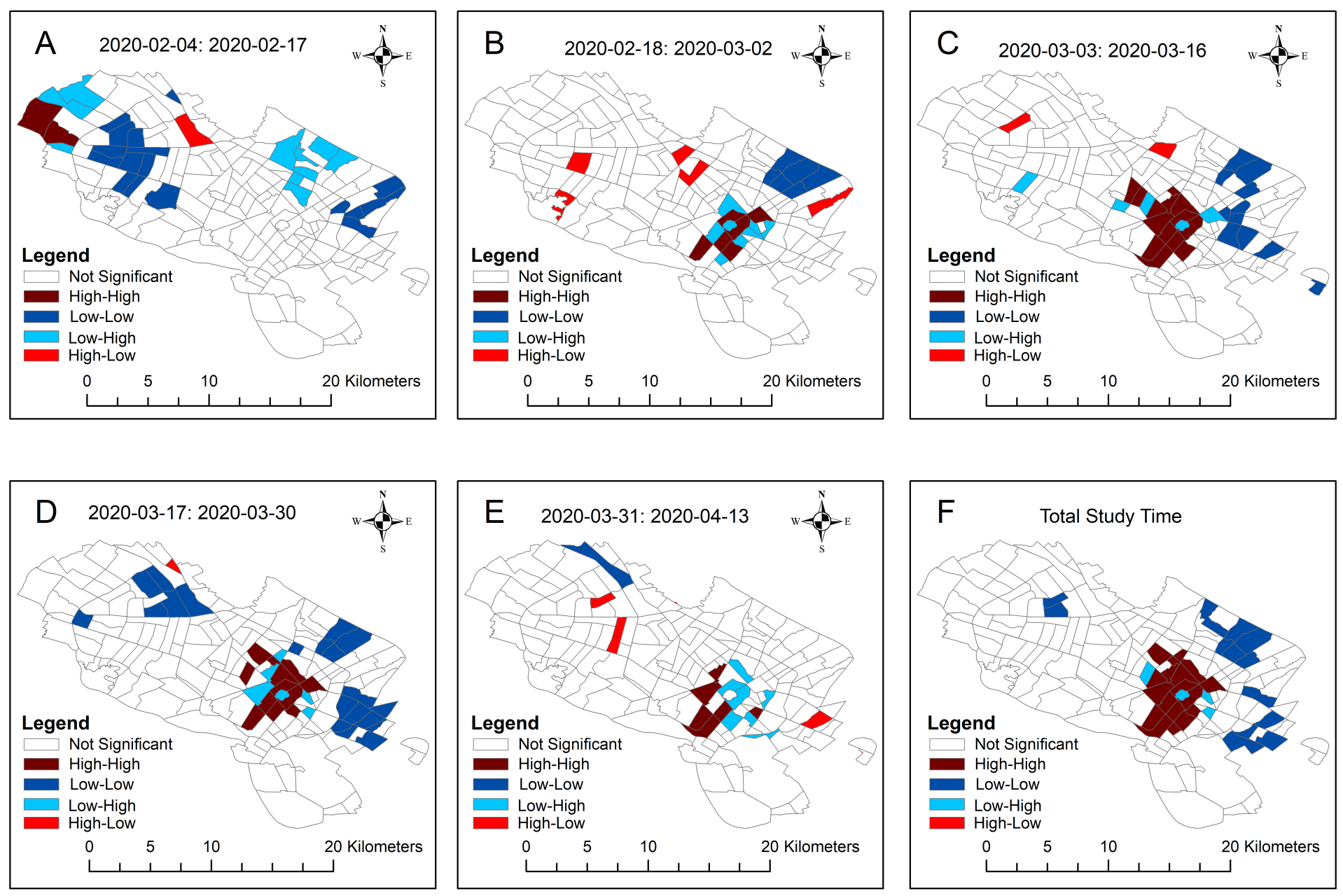

Figure 4

Spatial-time clusters of Covid-19 patients in the city of Mashhad 


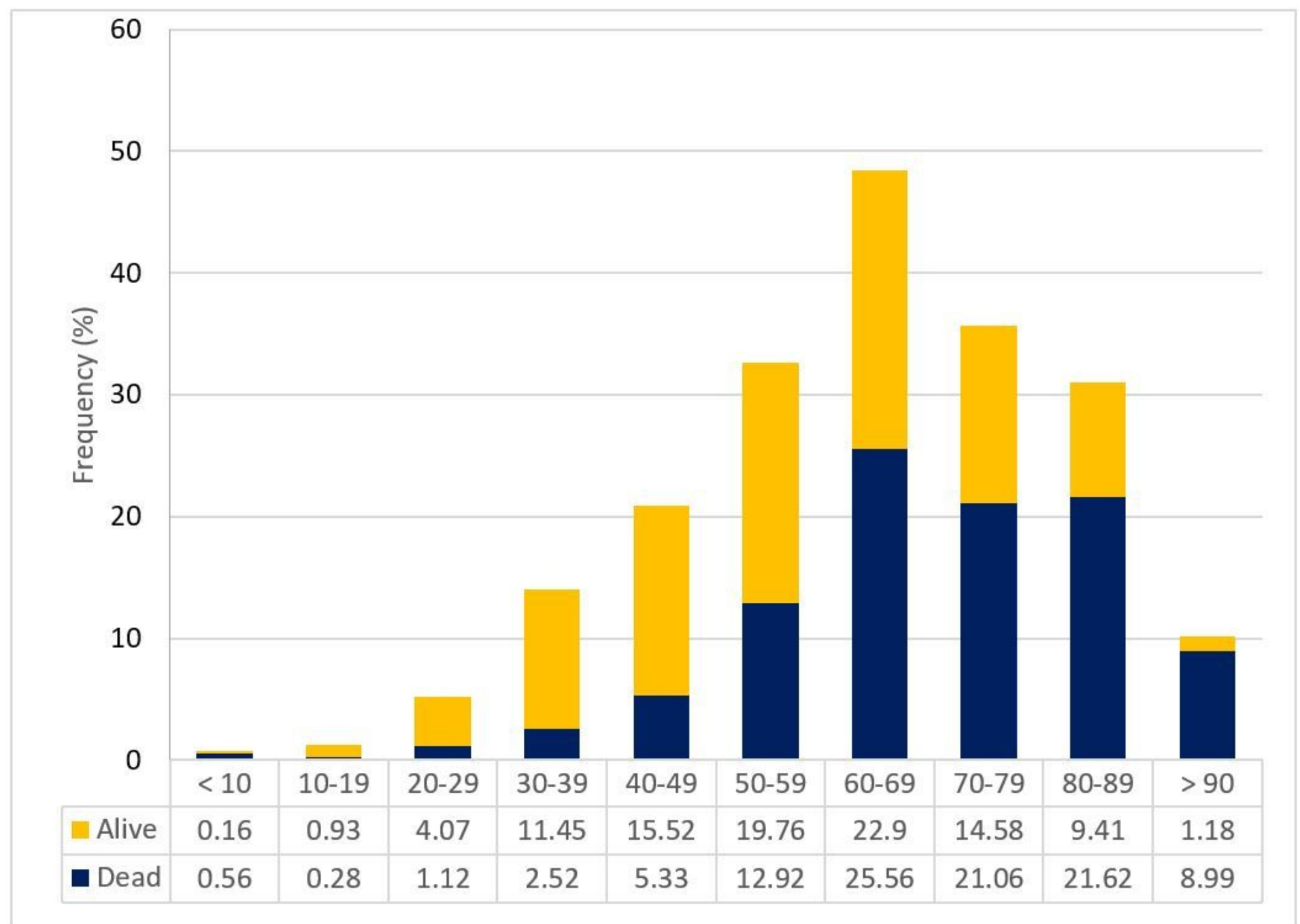

Figure 5

Spatial-time of Moran's scatter plots of Covid-19 patients in the city of Mashhad 